\title{
From petrography to nanoscale: new approach for 3D investigations of fossilized microorganisms from Mars analogue deposits
}

\author{
LARA MALDANIS ${ }^{1}$, LAURENCE LEMELLE ${ }^{2}$, DAVID \\ FERNANDEZ-REMOLAR ${ }^{3}$, MANUEL GUIZAR-SICAIROS $^{4}$, \\ MIRKO HOLLER ${ }^{4}$ AND ALEXANDRE S SIMIONOVICI ${ }^{5}$ \\ ${ }^{1}$ Université Grenoble Alpes \\ ${ }^{2}$ LGL-TPE, ENS de Lyon, Université de Lyon, CNRS \\ ${ }^{3}$ Institut de Biologie Structurale \\ ${ }^{4}$ Paul Scherrer Institute \\ ${ }^{5}$ University Grenoble Alpes \\ Presenting Author: lara.maldanis@univ-grenoble-alpes.fr
}

Studies of the early records of life on Earth have demonstrated the challenge for unequivocally identifying fossilized microorganisms [1]. The investigation of putative preserved microbes in rocks returned from Mars will require multiscale methods. Due to the difficulty of undisputedly identifying fossils at the cellular level, the access to nanoscale and 3D information are often critical [2-4]. Here we present a novel approach that allows micron-to-nanoscale $3 \mathrm{D}$ investigation of microfossils within $3 \times 3 \mathrm{~cm}$ petrographic thin sections, in a non-destructive and non-invasive way. We have studied fossilised filaments from the Rio Tinto iron rich acidic deposits, a geochemical and mineralogical analogue of Mars [5] After removal of the glass, samples were investigated by Ptychographic X-ray Laminography at the cSAXS beamline of the Swiss Light Source. Areas up to $180 \mathrm{~mm}^{2}$ were imaged, and details of fossils were obtained owing to the achieved half-period resolution of $110 \mathrm{~nm}$. With this multiscale imaging we assessed in 3D the morphology and geological context of the fossil filaments, contributing to the undertanding of how microorganisms are preserved in iron-rich acidic environments, such as on Mars. This approach does not require complex sample preparation, and due to its non destructive and non-invasive aspects, it can be particularly important for investigating precious or unique samples.

1. Javaux, E. J. Nature 572, 451-460 (2019).

2. Brasier, M. D., Antcliffe, J., Saunders, M. \& Wacey, D. Proc. Natl. Acad. Sci. 112, 4859-4864 (2015).

3. Wacey, D. et al. Precambrian Res. 220-221, 234-250 (2012).

4. Maldanis, L. et al. Sci. Rep. 10, 8163 (2020).

5. Amils, R. et al. Life 4, 511-534 (2014). 